\title{
Limitações no Uso das TICs em Serviços Bancários: estudo exploratório sob a percepção do usuário
}

\author{
Limitations on the Use of ICTs in Banking Services: exploratory study from the user's \\ perception of their limitations on access, behavior and cognition
}

Gabriella Ramos Tomás ${ }^{* 1}$ André Gustavo da Silva²

${ }^{1}$ Centro Universitário de João Pessoa, Paraíba, Brasil.

${ }^{2}$ Programa de Pós-Graduação em Administração, Paraíba, Brasil.

\begin{tabular}{|c|c|}
\hline INFO A R TIGO & RESUMO \\
\hline $\begin{array}{l}\text { Palavras-chave: } \\
\text { Limitações digitais, } \\
\text { TICs, } \\
\text { Serviços bancários. }\end{array}$ & $\begin{array}{l}\text { Esta pesquisa teve o objetivo de analisar as principais limitações digitais } \\
\text { encontradas pelos clientes diante da nova estrutura bancária que envolve } \\
\text { sistematização, automação e autoatendimento. Por se tratar de uma pesquisa } \\
\text { de mercado que buscou identificar o perfil sociodemográfico dos clientes } \\
\text { resistentes ao uso das Tecnologias de Informação e Comunicação (TICs) no } \\
\text { autoatendimento bancário em João Pessoa, julgou-se mais apropriado utilizar } \\
\text { uma ontologia fundacionista e epistemologia positivista suportada por uma } \\
\text { abordagem quantitativa. Destarte, por meio das análises realizadas sobre as } \\
\text { limitações digitais levantadas a partir dos clientes, concluiu-se que, apesar do } \\
\text { constante crescimento das TICs, existe um fenômeno recorrente no perfil dos } \\
\text { usuários que apresentam dificuldade em fazer efetivo uso das TICs, revelando } \\
\text { que os usuários que apresentam maior limitação cognitiva e comportamental } \\
\text { em utilizar os canais eletrônicos têm prevalência entre o público com mais de } \\
45 \text { anos e com escolaridade mediana. }\end{array}$ \\
\hline ARTICLE INFO & A B S T R A C T \\
\hline $\begin{array}{l}\text { Keywords: } \\
\text { Digital limitations, } \\
\text { ICTs, } \\
\text { Banking services. }\end{array}$ & $\begin{array}{l}\text { This research had as main objective analyze digital limitations customers } \\
\text { facing the new banking structure that involves systematization, automation } \\
\text { and self-service. In reason of it is a market research that seeks to identify the } \\
\text { sociodemographic profile of clients resistant to the use of Information and } \\
\text { Communication Technologies (ICTs) in banking self-service in João Pessoa, } \\
\text { it was considered more appropriate to use a positivist foundationalist and } \\
\text { epistemological ontology supported by a quantitative approach. In this way, } \\
\text { through the analysis performed about the digital limitations raised from } \\
\text { customers it is concluded that themselves despite the constant growth of ICTs, } \\
\text { there is a recurring phenomenon in the profile of users who experience } \\
\text { difficulties in performing effective use of ICTs revealing that users with } \\
\text { greater cognitive and behavioral limitations in using electronic channels have } \\
\text { a prevalence among the public over } 45 \text { years old and with medium schooling. }\end{array}$ \\
\hline
\end{tabular}

\footnotetext{
* Correspondência para autor: gabriellart@gmail.com (Tomás, G. R.), andregustavo2312@gmail.com (da Silva, A. G.).
} 


\section{Introdução}

Um dos setores que mais investe em tecnologia e automação é o setor bancário, assemelhando-se ao Governo, atingindo uma marca de R \$18,6 bilhões investidos em 2016 (FEBRABAN, 2017). A constante readequação na forma de utilização dos serviços prestados pelas instituições financeiras atinge a população indiscriminadamente, independentemente de sua faixa etária, situação econômica ou grau de instrução. Essa inovação experimentada pelo setor bancário nacional é reconhecida mundialmente e decorrente do investimento e da busca pelo aprimoramento dos sistemas.

Considerando que há um novo perfil de consumidor, as instituições bancárias buscam aprimorar suas soluções tecnológicas e têm se mostrado eficientes em suas estratégias de revolucionar o uso de novas tecnologias face ao atendimento presencial de qualidade. As operações realizadas por internet banking e mobile banking apresentaram $57 \%$ do total referente a todos os canais de atendimento efetivadas em 2016, ultrapassando pela primeira vez os canais convencionais (FEBRABAN, 2017).

Apesar da constatação do expansivo aumento do uso das Tecnologias de Informação e Comunicação (TICs) no setor bancário experimentadas nos últimos anos no Brasil e no mundo, nem todas as pessoas têm conhecimento e/ou habilidade suficientes para utilizar de forma efetiva os meios que os bancos disponibilizam para realização de operações financeiras. São esses usuários que mais sofrem com a mudança de cenário, uma vez que a maioria das operações, antes realizadas por meio do acesso direto às agências bancárias, tendem gradativamente a ser realizadas por meio de computadores e dispositivos móveis (smartphones e tablets).

Essa nova forma de comercialização dos bancos por meio das TICs proporciona vantagens aos clientes que estão mais familiarizados com a era digital, tal como minimização de tempo necessário para realizar pagamentos, saques, transferências e outros serviços, evitando longas filas de espera. $\mathrm{O}$ autoatendimento também os coloca em uma posição de maior controle sobre suas transações bancárias e poder de escolha, pois a facilidade de acesso à informação proporciona ao cliente meios de comparar qualidade e valor dos serviços oferecidos por outras instituições. A automação proporciona receitas com custos bem menores em relação à comercialização de produtos por intermédio de meios físicos e em contato direto com as agências e postos de atendimento. A utilização de meios digitais, portanto, reduz despesas com mão de obra, transporte de valores, arquivos em papéis e outros serviços. Deste modo, para a operacionalização de um serviço on-line, o cliente precisa dispor de equipamentos/acessibilidade (tablets, smartphones, notebooks, internet) que o auxiliem nas suas transações.

Diante do exposto, surge o seguinte questionamento: Quais as limitações digitais encontradas pelos clientes diante da nova estrutura bancária que envolve sistematização, automação e autoatendimento? Desse questionamento, resultou o objetivo deste trabalho que foi analisar as limitações digitais encontradas pelos clientes diante da nova estrutura bancária que envolve sistematização, automação e autoatendimento. A motivação do estudo foi saber quais fatores são mais relevantes para justificar a limitação ou incapacidade dos usuários que não acompanham esse redirecionamento para o autoatendimento. Para isso, foi aplicado um questionário com clientes correntistas de uma instituição financeira bancária na cidade de João Pessoa, para identificar com qual frequência fazem uso das TICs (caixas eletrônicos, internet banking, mobile banking, bankphone etc.), assim como em qual proporção se dirigem às agências e aos postos de atendimento para realizar suas transações financeiras e bancárias.

Esta pesquisa se torna relevante à medida que se inspira em um modelo de mensuração das limitações ao uso das TICs validado academicamente, tendo por fito otimizar a prática da gestão nos serviços bancários oferecidos por uma de suas agências mediante uma melhor compreensão do perfil e do comportamento de usuários que não fazem uso dos meios de autoatendimento para realizar suas transações financeiras e bancárias, e, mais ainda, a compreender quais os principais fatores que dificultam a aceitação de tais tecnologias e, por conseguinte, a readequação dos sistemas de acordo com as reais habilidades e necessidades dos clientes. Assim, considerando a perspectiva e tendência de que os bancos em um futuro próximo readequarão seu modelo de negócio com perspectiva de predominância no meio digital, é importante dar suporte aos usuários que não fazem uso das TICs para que os mesmos possam aproveitar efetivamente os benefícios dessa modernização.

\section{Intensificação do uso das TICs}

A Sociedade contemporânea tem experimentado grandes progressos por meio do uso das TICs. Isso é possível devido à quantidade crescente de informações que se pode coletar, processar e tornar acessível a outras pessoas. Por meio do uso efetivo da tecnologia da informação, os indivíduos têm a oportunidade de redefinir a forma como conduzem suas vidas cotidianas; e as sociedades, de proporcionar saltos qualitativos no tocante ao desenvolvimento econômico e à elevação do padrão da qualidade de vida de sua população. 
A transformação digital inaugura uma era de mudanças sem precedentes na forma como as pessoas se relacionam, tanto na vida pessoal quanto no mundo corporativo, criando inúmeros desafios e oportunidades. As tecnologias sociais móveis e analíticas contribuíram para a transformação do comportamento do consumidor e dos negócios orientada para o digital. Em todos os setores, a necessidade de integração ou interconectividade entre vários sistemas, bancos de dados e dispositivos é reconhecida como requisito para oferecer uma experiência exitosa aos usuários do sistema. Um exemplo bastante claro do processo de transformação digital que permeia a sociedade contemporânea pode ser evidenciado pelo constante esforço de readequação na forma de utilização dos serviços prestados pelas instituições financeiras que atinge a população indiscriminadamente, uma vez que a maior parte dos cidadãos adultos, independentemente da faixa etária, situação econômica ou grau de instrução, já precisou pelo menos uma vez utilizar esse serviço.

Para que se obtenha efetividade no atendimento às demandas dos clientes, não será suficiente apenas introduzir a modernização das TICs no setor de prestação de serviços bancários, mas sim desenvolver a crença de utilidade do sistema entre seus usuários, porquanto a importância das TICs, enquanto pilares mediadores do autoatendimento, e a facilidade para o seu uso efetivo devem ser melhor compreendidas tanto pelo prestador de serviços quanto pelos usuários (SARANYA, 2014).

A exclusão digital é uma das questões mais críticas na economia do conhecimento. Hsieh, Rai e Keil (2008) afirmam que os setores público e privado têm dedicado recursos vultosos para enfrentar essa questão, mas os resultados ainda são bastante incipientes. Ressaltam ainda que as investigações que se dedicam a aprofundar o conhecimento sobre quem são os excluídos, bem como entender os porquês de sua exclusão tornam-se imprescindíveis para que se possa expandir a compreensão tanto sobre a desigualdade digital quanto para informar a efetiva formulação e intervenção de políticas de inclusão.

Dewan e Riggins (2005) argumentam que a desigualdade digital se refere à separação entre aqueles que têm acesso à informação digital e tecnologia de comunicações (TIC) e aqueles que não têm. Muitos acreditam que o acesso universal às TICs traria uma comunidade global de interação, comércio e aprendizado, resultando em padrões mais elevados de vida e melhoria do bem-estar social. No entanto, o abismo digital ameaça esse resultado, levando muitos formuladores de políticas públicas a debater sobre a melhor maneira de superar os diversos níveis de exclusão. Grande parte das pesquisas sobre a exclusão digital limitam-se a indicar quem tem acesso à tecnologia, entretanto, estudos mais criteriosos têm abordado a perspectiva da desigualdade na capacidade de uso da tecnologia entre aqueles que possuem acesso, mas que não fazem o seu uso efetivo. É preciso desvendar qual ou quais resistências impedem esses indivíduos de se integrar e de assumir um maior protagonismo na era digital, passando a usufruir das facilidades disponíveis por meio das TICs.

A resistência do usuário à implementação de sistemas de informação foi identificada como uma razão para o fracasso de novos sistemas e, portanto, precisa ser compreendida e gerenciada. Kim e Kankahalii (2009) ressaltam que, embora muitas pesquisas tenham explorado as razões da resistência do usuário, existem lacunas em nossa compreensão de como estes avaliam a mudança para um novo sistema de informação e decidem resistir a ela. Em particular, a lacuna na explicação da tomada de decisão do usuário é o conceito de viés de status quo, ou seja, que a resistência do usuário pode ser devido ao viés ou preferência para ficar com a situação atual.

\section{TICs e o setor bancário}

A tecnologia da informação e comunicação permeia diversos setores da sociedade contemporânea. Elas estão presentes nos estabelecimentos para organizar filas, identificar preços, solicitar formulários, agendar consultas, gerar boletos, entre outros serviços, inclusive votar. Essa era digital promove e estimula o seu uso, pois, por meio dela, é possível gerir com eficiência mais de um setor de uma organização, dado sua dinamicidade no uso e, como ferramenta, capacidade de armazenar dados.

A prestação de serviços bancários já não se limita aos balcões das agências físicas, para onde os clientes precisavam se dirigir e aguardar o atendimento presencial. A mediação do autoatendimento por meio das TICs tem demandado um vultoso investimento do setor bancário que tem refletido em oportunidade de rapidez e conveniência aos usuários que fazem uso efetivo dessa facilidade, bem como resistência por parte de outra parcela de usuários com perfil mais conservador e, por conseguinte, resistente às mudanças decorrentes das novas TICs utilizadas nas operações de autoatendimento. Yousafzai (2012) afirma que a adoção de TIC Banking é um processo complexo e multifacetado, de modo que uma consideração conjunta dos aspectos pessoais, sociais, psicológicos, utilitários e comportamentais dos clientes é mais importante do que a própria modernização das TICs e resultará 
no comportamento pretendido. Alguns estudos realizados por pesquisadores indianos buscando maior compreensão sobre o uso de TIC no setor bancário e sobre como as pessoas fazem uso de seus produtos e serviços sugerem que os formuladores de políticas devem enfatizar os atributos úteis do sistema bancário de TIC ao tentar aumentar seu uso por pessoas que já o utilizam (SARANYA, 2014).

Dados publicados em 2017 pela FEBRABAN corroboram a intensificação do autoatendimento mediado pelo uso das TICs na realização das operações bancárias, demonstrando que as operações realizadas por internet banking e mobile banking representaram 57\% do total das operações bancárias realizadas em 2016, dentre as quais, $34 \%$ foram realizadas pelo celular e $23 \%$ pela internet banking, totalizando 36,7 bilhões de operações feitas pelos brasileiros em 2016 (FEBRABAN, 2017).

Neste sentido, entender de que forma o efetivo uso das TICs têm sido incorporadas pelos usuários torna-se imperativo para que as organizações possam oferecer serviços compatíveis com as necessidades de diversos perfis de clientes. Com esse objetivo, foram desenvolvidos diversos estudos sobre como as tecnologias de informação e comunicação assumem papel indispensável para que o homem exerça sua cidadania (MELLO; STAL; QUEIROZ, 2006; BELLINI; GIEBELEN; CASALI, 2010).

\section{TICs e TCP}

Uma das principais preocupações dos pesquisadores entusiastas dos Sistemas de Informação na atualidade consiste em desbravar as motivações dos usuários em aderir ou não a adoção das TICs em suas atividades diárias. Um dos modelos mais festejados para medir esse nível de aceitação é o modelo TAM (Technology Acceptance Model) do Davis (1989), que busca avaliar o fenômeno sob duas vertentes: a primeira voltada para a aceitação por meio da utilidade percebida do usuário da TIC, e a segunda, voltada para a facilidade de uso percebida por esse usuário. Apesar de reconhecer a validade do Modelo TAM na contemporaneidade, esta pesquisa optou por embasar-se em modelo diverso, uma vez que buscou avaliar possíveis limitações dos usuários das TICs, razão pela qual optou por usar o Modelo Tridimensional proposto por Bellini, Giebelen e Casali (2010), que possibilita uma compreensão aprofundada sobre as limitações digitais, considerando suas dimensões de maneira multifacetadas, combinando diferentes formas de limitações para entender quais as barreiras encontradas pelo indivíduo no uso efetivo das TICs. Eles classificam as limitações digitais sistematicamente em limitações de acesso, limitação cognitivo-informacional e limitação comportamental, todas interdependentes e baseadas na teoria do comportamento planejado.

O modelo descreve a limitação de acesso (LA) como a dificuldade do indivíduo em ter acesso às TICs, quer seja por fatores sociais ou materiais, a exemplo de não dispor de equipamentos (tablets, smartphones, notebooks), sistemas de softwares inadequados, layouts de aplicações complexas etc. A limitação cognitivo-informacional (LI) trata da deficiência do usuário ou dificuldade para utilizar efetivamente as TICs. Elas podem ser manifestadas no saber manusear as ferramentas de pesquisa, seleção e aplicação das informações obtidas por meio das TICs.

A LI pode ser causada por diversos fatores neurológicos e psicológicos. Nesse ponto, é válido ressaltar que a formação do indivíduo contribui imensamente para o desenvolvimento de suas habilidades. Portanto, a construção de um ensino associado a esse desenvolvimento tecnológico é de extrema importância para mitigar a exclusão digital. No mais, para os que já passaram da fase do ensino básico, a alfabetização digital, termo aqui utilizado para descrever ações que promovam a inclusão de adultos nessa nova era, é um meio de reintegrar os cidadãos, promovendo sua participação efetiva na sociedade, com maior qualidade de vida.

A limitação comportamental (LC) refere-se à barreira que o indivíduo encontra em aplicar de forma eficaz suas habilidades digitais. "Essas dificuldades podem incluir desde um bloqueio psicológico ao uso das TICs até um uso excessivo das mesmas" (BELLINI, GIEBELEN E CASALI, 2010). A LC relaciona-se a comportamentos positivos no que se refere às TICs, simplificando processos, reduzindo tempo de espera em filas, facilitando a comunicação etc.; ou negativamente, como propagando conteúdos maliciosos, utilização por longos períodos de tempo a ponto de protelar outras atividades etc.

Partindo desse contexto, a Teoria do Comportamento Planejado (TCP), proposta pelo psicólogo social Icek Ajzen em 1985, tem grande valia para entender o aspecto comportamental do não usuário das TICs. Seu modelo multidimensional apresenta uma definição objetiva e consistente para o aspecto 'atitude' e por isso serve como referência até os dias atuais para pesquisas sobre o comportamento humano.

Ela sugere que as intenções comportamentais são determinadas por três construtos independentes. O primeiro deles, que se refere ao grau com que uma pessoa tem uma 
avaliação favorável ou desfavorável em relação a um comportamento, é denominado atitude. O segundo é um fator social denominado norma subjetiva e refere-se à pressão social percebida para manifestar ou não o comportamento. Por fim, o terceiro preditor das intenções comportamentais é o grau de controle comportamental percebido. Ele refere-se à facilidade ou dificuldade percebida para exibir o comportamento (Ajzen apud Heidmann, 1991).

Esse fenômeno de intensificação do uso das TICs no setor bancário constatado nos últimos tempos é facilmente respaldado à luz da TCP, em que a intenção comportamental do indivíduo é frequentemente estimulada para que ele manifeste o comportamento favorável ao uso das TICs, enquanto parte da sociedade que tem dificuldade para atender a esses estímulos é de certa forma prejudicada por não acompanhar o novo e frenético ritmo bancário que, com apenas um clique, finaliza suas operações financeiras.

\section{Procedimentos Metodológicos}

Por se tratar de uma pesquisa de mercado que buscou identificar o perfil sociodemográfico dos clientes resistentes ao uso das TICs no autoatendimento bancário em João Pessoa, julgou-se mais apropriado utilizar uma ontologia fundacionista e epistemologia positivista suportada por uma abordagem quantitativa.

A pesquisa pode ser classificada como exploratória e descritiva, haja vista buscar realizar investigações iniciais por meio da realização de revisão da literatura, seguida pela descrição do perfil sociodemográfico dos clientes bancários resistentes ao uso das TICs no autoatendimento.

As pesquisas exploratórias são frequentemente indicadas para as fases de revisão da literatura, formulação de problemas, levantamento de hipóteses, identificação e operacionalização das variáveis. (GIL, 2002). Samara e Barros (2002) acrescentam, ainda, que, em um projeto de pesquisa, o estudo exploratório pode ser essencial para, num primeiro momento, determinar uma situação de mercado a partir de informações sobre a concorrência, produtos existentes, evolução e tendências de um segmento específico em que se pretenda atuar; tendo como grande vantagem o fato de demandar um baixo custo no que se refere à obtenção das informações, uma vez que se parte de dados já existentes e de conversas informais. Contudo, tem a desvantagem de, geralmente, encontrar informações defasadas, já que no Brasil existe a dificuldade de se obter dados atualizados nos órgãos oficiais que se destinam a pesquisa.

As pesquisas descritivas preocupam-se com a descrição das características de determinada população ou fenômeno e/ou com o estabelecimento de relações entre as variáveis. Como, por exemplo, as pesquisas que têm por objetivo estudar as características de determinado grupo - nível de escolaridade, religião, renda etc. (GIL, 2002). A pesquisa descritiva utiliza técnicas padronizadas de coleta de dados como o questionário, formulário e a observação sistemática. Em outros termos, pode-se dizer que a pesquisa estatística descritiva objetiva apresentar características de uma situação, um grupo ou indivíduo específico e verificar a frequência com que algo ocorre, ou com o que está ligado. Samara e Barros (2002) dizem que o estudo descritivo estatístico quantitativo busca quantificar as relações de consumo, respondendo principalmente à questão "Quanto?" para cada objetivo da pesquisa. Esses estudos são realizados através de amostragem, em que se procura estimar os parâmetros populacionais a partir dos resultados obtidos no levantamento amostral, estudando-se os estimadores, médias e proporções.

Foi utilizado como ferramenta de pesquisa um questionário formulado com dezoito questões inspiradas no estudo de Bellini, Giebelen e Casali (2010), que define como limitações digitais: limitações de acesso, limitações cognitivo-informacional e limitação comportamental. Para cada construto, foram efetuadas perguntas com base em alegações já identificadas por meio de análises empíricas de possíveis fatores de limitação de acordo com a renda. A população analisada era composta de 4412 pessoas até a data de 16 de novembro de 2018. A amostra utilizada foi de 146 respondentes, com margem de erro de $8 \%$ e nível de confiança de $95 \%$.

\section{Resultados}

\subsection{Limitações de acesso}

A limitação de acesso (LA) é a primeira premissa no que tange à utilização ou não das TICs. Ela parte do conceito de que, para fazer uso efetivo das TICs é necessário o acesso do indivíduo a um dispositivo eletrônico. 
Dos 146 usuários respondentes, apenas 18 não o possuíam.

A seguir, para cada pergunta proposta, os gráficos demonstram o perfil dos clientes que fazem uso das TICs de forma efetiva ou não, em que o eixo das ordenadas do gráfico representa a quantidade de respondentes para cada conglomerado; e as abcissas, suas características descritivas.

Gráfico 1 - Possuo um dispositivo eletrônico (smartphone, notebook, tablet, etc).

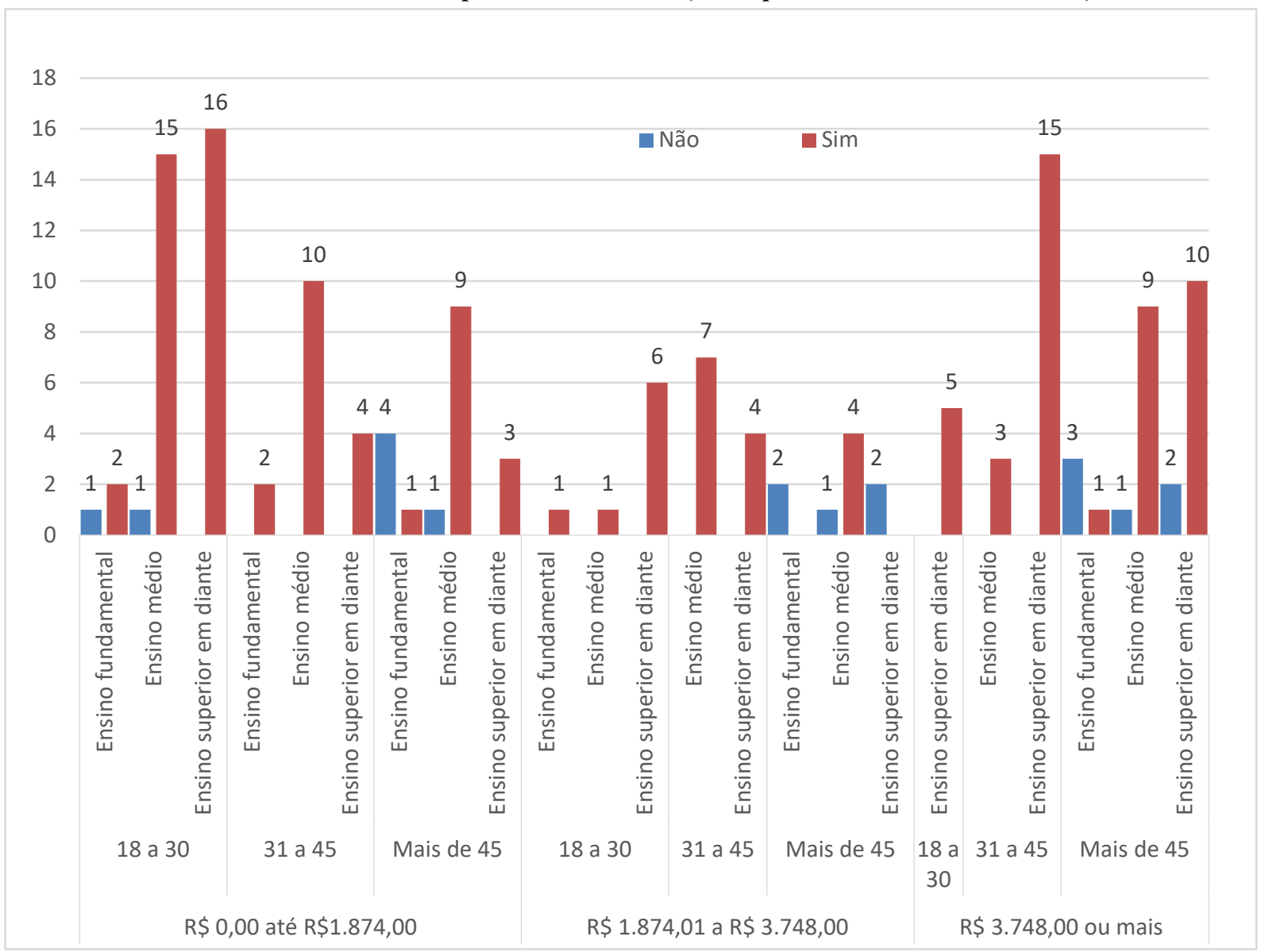

Fonte: Elaborado pelo autor (2019)

Constatou-se um elevado número de pessoas detentoras de dispositivos eletrônicos. De acordo com o gráfico 1, de 146 entrevistados, 128 afirmaram possuir um disposito eletrônico. O perfil em destaque no gráfico possui idades entre 18 a 30 anos, nível de escolaridade superior e renda média de até R\$1.874,00.

O perfil em destaque, que não possui um dispositivo eletrônico, caractetiza-se por ter mais de 45 anos, ensino fundamental e renda de até $\mathrm{R} \$ 1.874,00$. Das 18 pessoas que informaram não possuir dispositivo eletrônico, apenas duas têm entre 18 e 30 anos, os demais têm mais de 45 anos. 
Gráfico 2 - Possuo internet móvel ou doméstica.

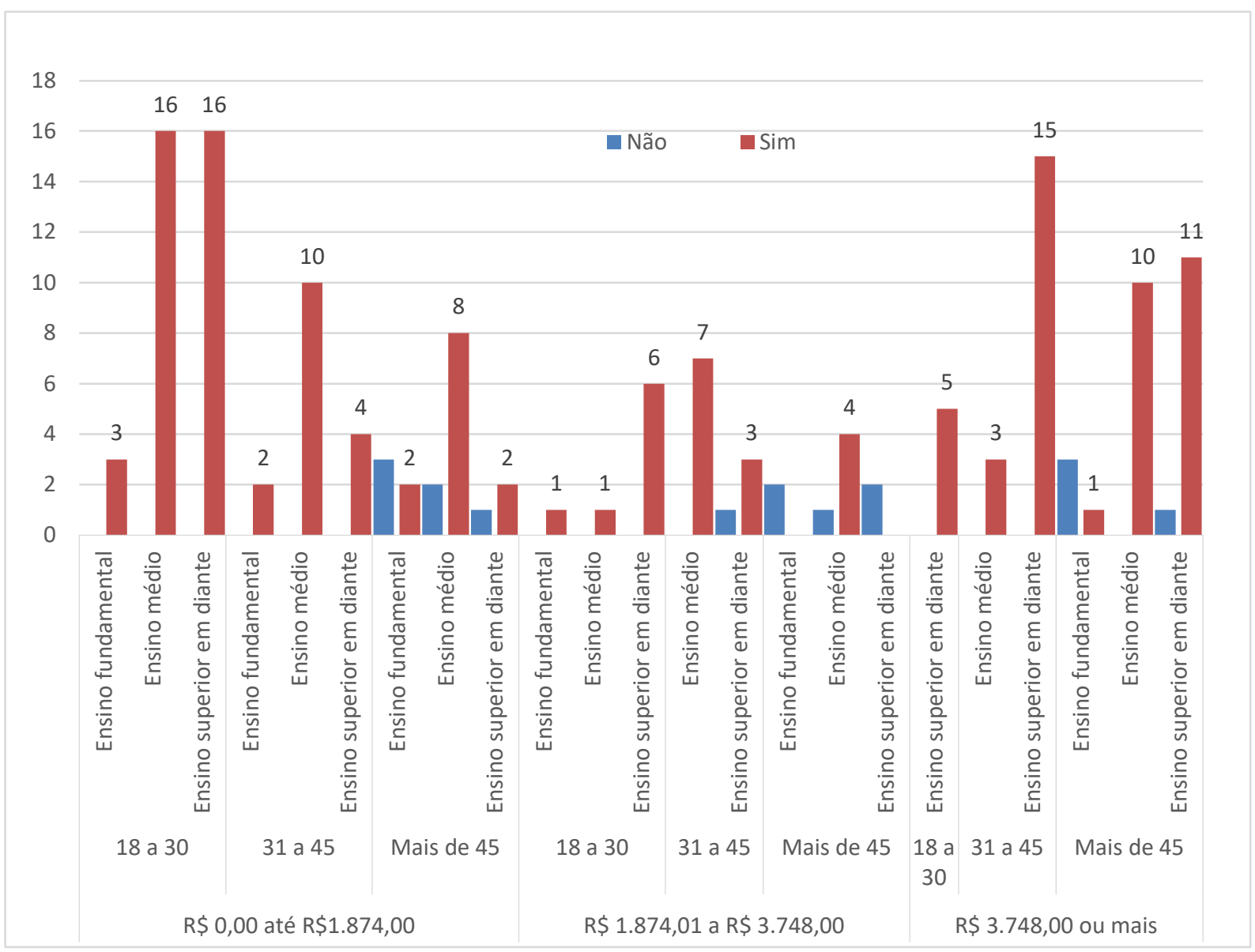

Fonte: Elaborado pelo autor (2019).

Diante das informações do gráfico 2, os usuários que alegaram não possuir internet móvel ou doméstica no universo de 146 respondentes foi de 16 pessoas. Apesar de ser um número reduzido, a pesquisa aponta novamente uma tendência. Do total dos 16 respondentes que alegaram não possuir internet, 15 deles, independente da renda e com diferentes níveis de escolaridade, têm idade acima de 45 anos; o outro, está na faixa etária de 31 a 45 anos. Dos entrevistados que não possuem internet móvel ou doméstica, a maioria também possui escolaridade de até o ensino médio, representando 11 dos 16 usuários.

Dos 146 entrevistados, 48 têm idade entre 18 e 30 anos. Todos os respondentes dessa faixa etária afirmaram possuir internet móvel ou doméstica. De 48 pessoas, 35 possuem renda de até $\mathrm{R} \$ 1.874,00$ reais, e são subdivididos em 16 com ensino superior, 16 com ensino médio, e apenas 3 com ensino fundamental. Comprovando novamente que o fator renda não foi o mais relevante para a resistência ao uso dos dispositivos, mas sim a combinação escolaridade e idade. 
Gráfico 3 - Possuo e faço uso do aplicativo do meu banco.

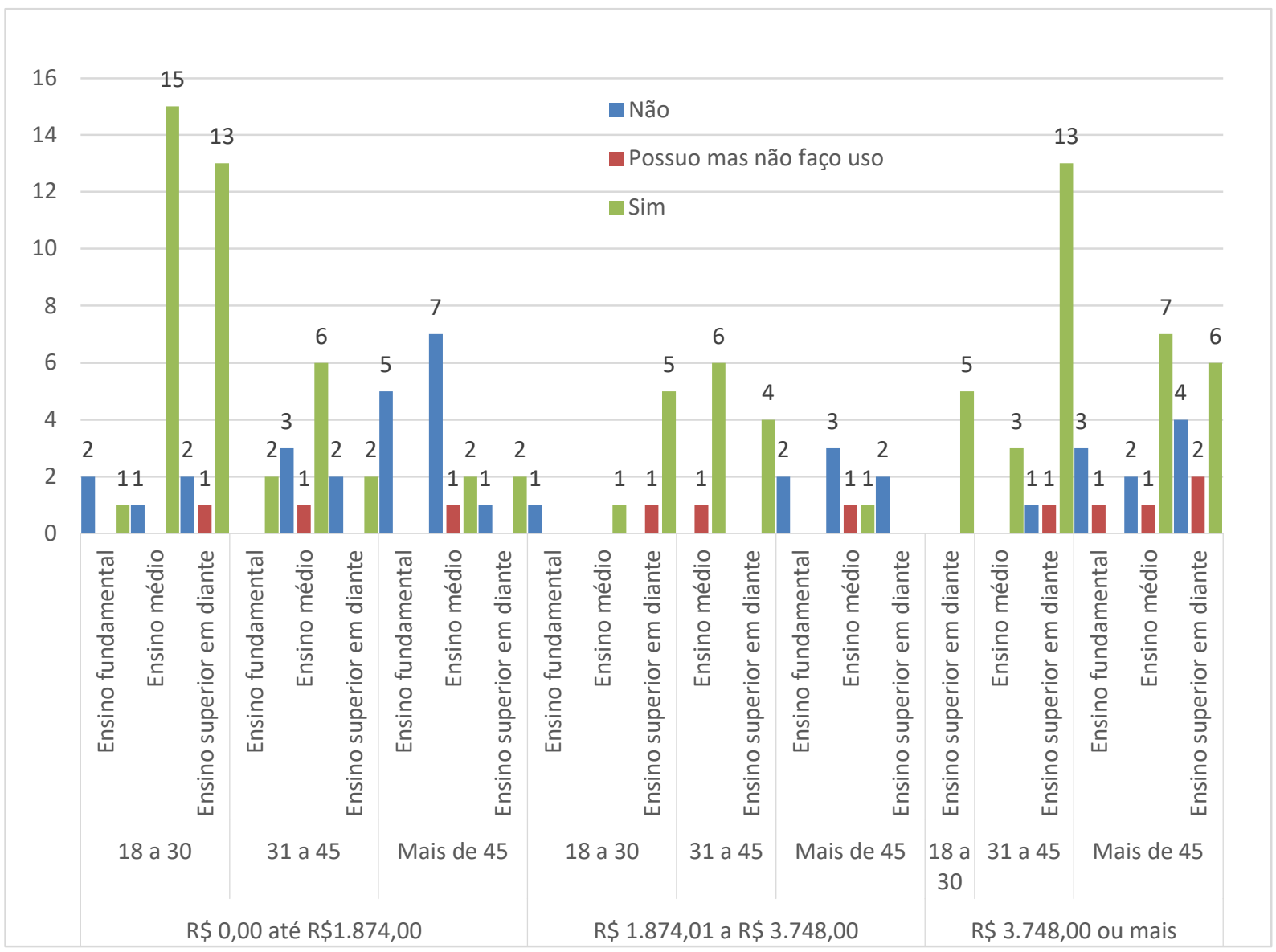

Fonte: Elaborado pelo autor (2019).

Quando questionados se possuíam e utilizavam o aplicativo do banco, o número de usuários do total dos respondentes caiu para 94, conforme demonstra o gráfico 3. A pesquisa contabilizou 17 respondentes do ensino fundamental e destes, apenas 3 disseram possuir e utilizar o aplicativo do banco. O perfil que se destacou neste indicador possui entre 18 e 30 anos, ensino médio e renda de até $\mathrm{R} \$ 1.874,00$, totalizando 15 respondentes; seguido do perfil de 31 a 45 anos, ensino superior em diante e renda acima de $\mathrm{R} \$ 3.748,00$ e perfil de 18 a 30 anos com ensino superior em diante e renda de até $\mathrm{R} \$ 1.874,00$, ambos igualmente com 13 respondentes. O perfil que informou não possuir e não utilizar o aplicativo do banco se caracteriza, em sua maioria, por ter mais de 45 anos, ensino médio e renda de até $\mathrm{R} \$ 1.874,00$, com 7 respondentes do total de 41 pessoas que marcaram essa opção.

Esses dados corroboram com a segunda premissa da teoria do comportamento planejado (AJZEN, 1991a), em que o fator social, por meio de estímulos do sistema bancário para obtenção dos aplicativos, impulsiona para a manifestação favorável ao uso das TICs. Contudo, nem todos os usuários, ainda que possuam o acesso de fato, fazem sua efetiva utilização. Os 52 respondentes que não faziam uso dos aplicativos para efetuarem suas transações financeiras, seja por não terem o acesso ou por apenas não manifestarem o comportamento positivo para essa tendência pode ser justificada pelo terceiro preditor da TCP, que se refere à facilidade ou dificuldade percebida pelo indivíduo para exibir o comportamento (AJZEN, 1991a).

\subsection{Limitações cognitivo-informacional}

A limitação cognitivo-informacional (LI) foi a mais complexa de analisar, pelo fato de, em muitos casos, o público não ter consciência das suas limitações, não reconhecer a sua existência ou não manifestar o interesse em realizar suas transações com autonomia (sempre necessitando que alguém os conduza no momento de buscar, selecionar, processar e aplicar as informações no momento que precisavam utilizar as TICs). 
Gráfico 4 - Tenho dificuldade na utilização dos canais eletrônicos que o banco dispõe.

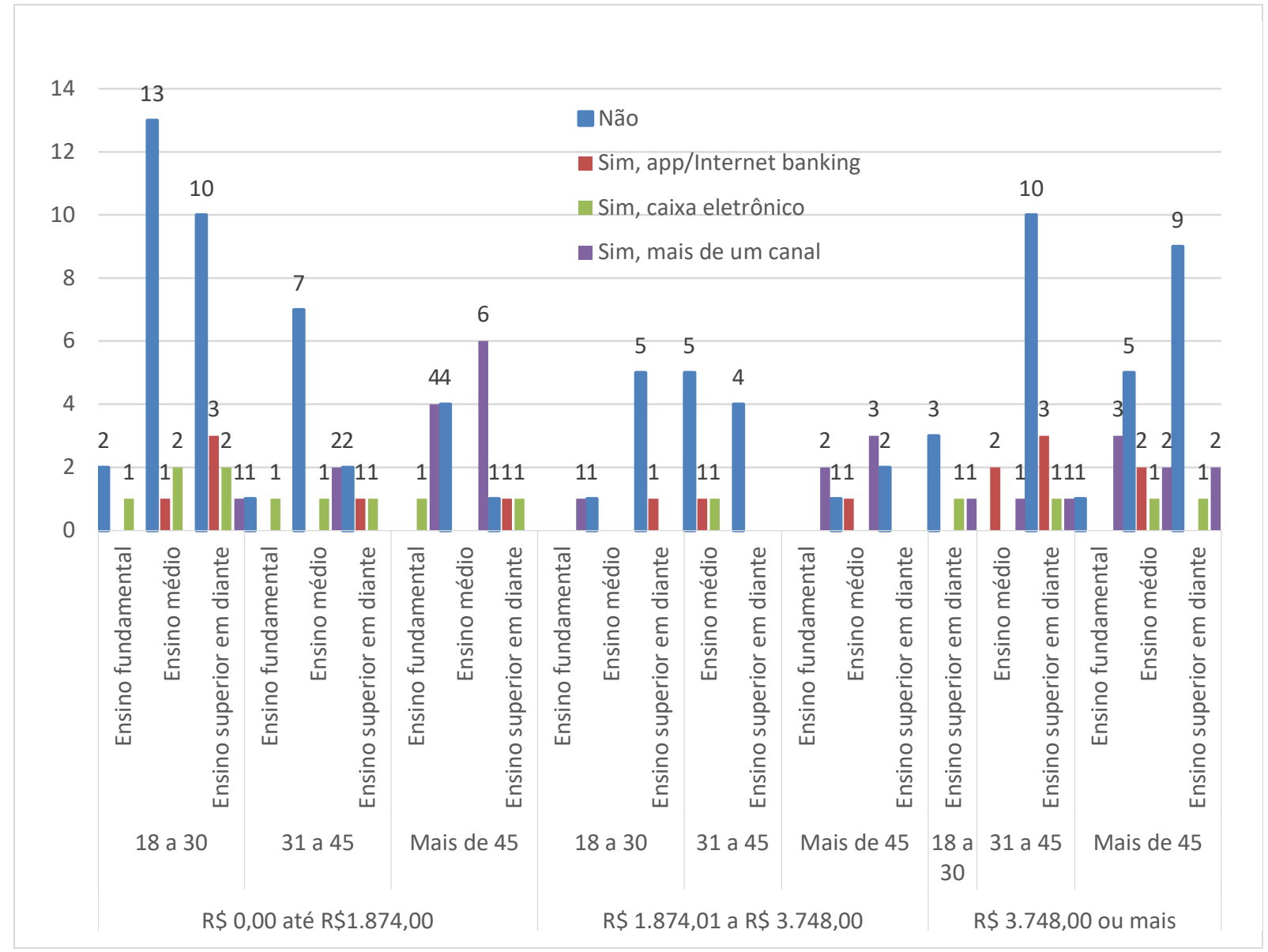

Fonte: Elaborado pelo autor (2019).

Nesse público, 50 pessoas, dos 146 respondentes, alegaram ter dificuldade em um ou mais de um canal eletrônico, como demonstra o gráfico 4. Dentro dessas afirmações, o perfil que alegou ter dificuldade em mais de um canal foi de 26 pessoas, com destaque para o público com mais de 45 anos e escolaridade até o ensino médio, que caracterizou 23 desses respondentes. Os outros três possuiam rendas e escolaridades diferentes, sem demonstrar quaisquer características em comum além de ter 18 a 30 anos.

Do total dos 50 respondentes, 10 relararam ter dificuldade na utilização dos caixas eletrônicos, distribuídos entre as três dimensões de renda, com destaque para o perfil de 31 a 45 anos, renda de até $\mathrm{R} \$ 1.874,00$ e ensino médio. Notou-se também que nenhum respondente dentro do perfil de 18 a 30 anos marcou essa opção.

O público que marcou ter dificuldade no aplicativo/internet banking foi de 14 pessoas, o destaque foi para o perfil de 18 a 30 anos, com renda de até $\mathrm{R} \$ 1.874,00$ e ensino superior em diante. No geral, se dividiram equilibradamente entre renda, escolaridade e idade, apesar de apenas 1 pessoa com ensino fundamental ter marcado essa opção.

Dos 96 respondentes que alegaram não ter dificuldade na utilização dos canais eletrônicos, dois perfis tiverem o mesmo número de respondentes com 14 em cada. O perfil de 18 a 30 anos com renda de até $\mathrm{R} \$ 1.874,00$ e ensino médio, e o perfil de 31 a 45 anos, com renda acima de $\mathrm{R} \$ 3.748,00$ e ensino superior; seguidos do perfil de 18 a 30 anos, com ensino superior e renda de até $\mathrm{R} \$ 1.874,00$. Apenas 4 dos 96 respondentes que alegaram não ter dificuldade possuiam o ensino fundamental, e nenhum deles possuia mais de 45 anos. 
Gráfico 5 - Sinto-me pressionado (a) pela agilidade que os ATMs demandam no momento de selecionar as opções de comando.

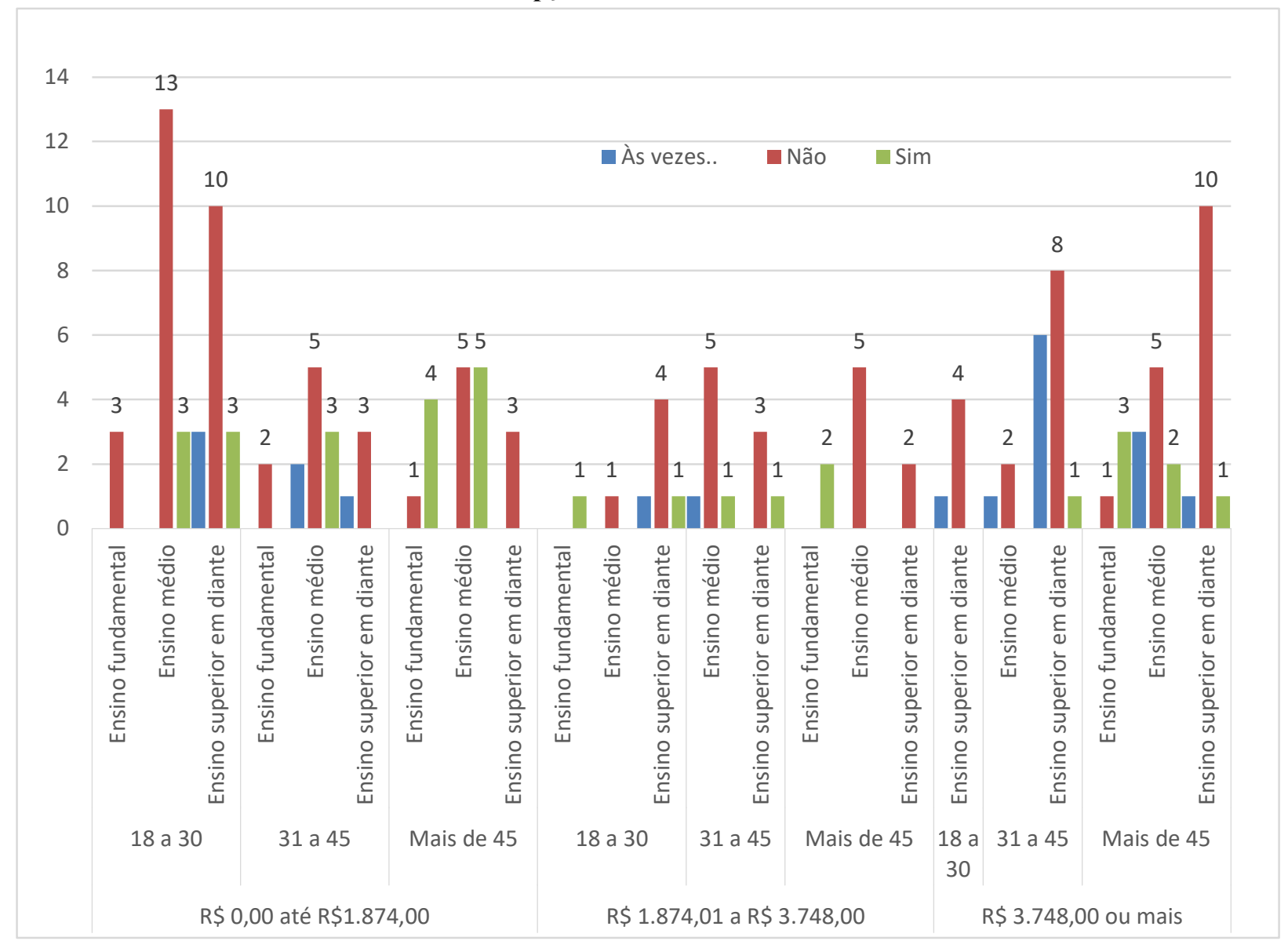

Fonte: Elaborado pelo autor (2019).

O gráfico 5 revela 31 respondentes que alegaram sentir-se pressionados pela agilidade que os autoatendimentos demandam no momento de selecionar as opções de comando. O perfil que teve destaque foi o com mais de 45 anos, escolaridade ensino médio e renda até $\mathrm{R} \$ 1.874,00$, seguido do grupo de mesmo perfil com escolaridade ensino fundamental, juntos, correspondem a 9 pessoas. Desse grupo, 17 possuía mais de 45 anos, sendo maioria e evidenciando perfis identificados em outro questionamento, como o "tenho dificuldade na utilização dos canais eletrônicos que o banco dispõe”.

O perfil que respondeu "às vezes" para esse questionamento estava na faixa etária entre 31 e 45 anos, com ensino superior e renda superior a R \$3.748,00. Deste total, 20 usuários marcaram esta opção. Os que se encaixaram neste perfil, informaram se sentir pressionados psicologicamente quando utilizam as TICs por fatores emocionais vastos e até desconhecidos por eles próprios.

Do total de respondentes, a maioria alegou não se sentir pressionado pela agilidade que os autoatendimentos demandam, sendo 96 pessoas que marcaram essa opção. O perfil que se destacou possuía entre 18 a 45 anos, com escolaridade ensino médio e renda até $\mathrm{R} \$ 1.874,00 \mathrm{com} 13$ respondentes; seguido do grupo de pessoas com mais de 45 anos, ensino superior e renda acima de $\mathrm{R} \$ 3.748,00$ com 10 respondentes e o grupo com idade entre 18 a 30 anos, ensino superior e renda até $\mathrm{R} \$ 1.874,00$, também com 10 respondentes. 
Gráfico 6 - As telas de navegação são complexas.

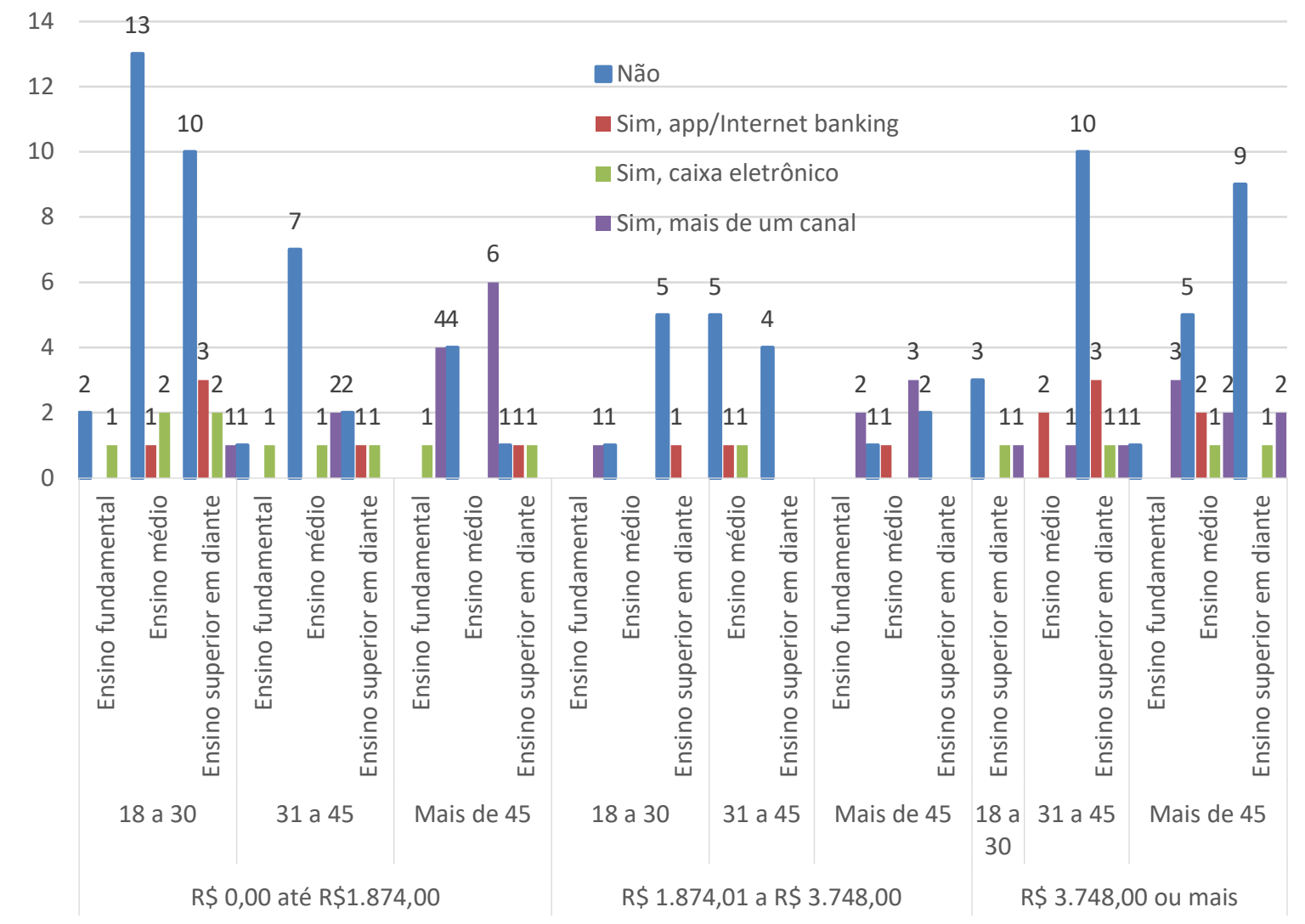

Fonte: Elaborado pelo autor (2019).

O público que afirmou que as telas de navegação das TICs em mais de um canal são complexas foi de 29 respondentes, como mostra o gráfico 6. Dentro desse número, o perfil em destaque possuía mais de 45 anos, escolaridade ensino médio e renda de até R\$ 1.874,00, seguido por $4 \mathrm{com}$ as mesmas características, sendo a escolaridade ensino fundamental. Apenas 5 pessoas do ensino superior marcaram essa opção, distribuídos por idade e rendas diferentes.

Dos 15 respondentes que marcaram a opção 'caixa eletrônico como tela de navegação complexas', 10 possuíam renda de até $\mathrm{R} \$ 1.874,00$. Porém, analisando o perfil em conjunto com a renda e escolaridade, apenas dois perfis se destacaram, o de 18 a 30 anos com renda de até R\$ 1.874 e escolaridade distinguidas em ensino fundamental e médio. Ainda assim com uma diferença reduzida de apenas um respondente a mais.

Quanto aos que negaram que as telas que navegação são complexas, foram maioria e totalizou 86 pessoas. O perfil em destaque tinha idade de 18 a 30 anos, ensino médio e renda de até R $\$ 1.874,00$; seguido do perfil de igual renda e idade com escolaridade ensino superior, e o perfil de 31 a 45 anos com ensino superior e renda acima de $\mathrm{R} \$ 3.748,00$.

\subsection{Limitações comportamentais}

As limitações comportamentais analisadas dizem a respeito à disposição do cliente em aplicar suas habilidades digitais, quando existentes, por meio da utilização dos canais eletrônicos para realizar suas transações. 
Gráfico 7 - Tenho receio quanto à segurança das minhas informações nos aplicativos.

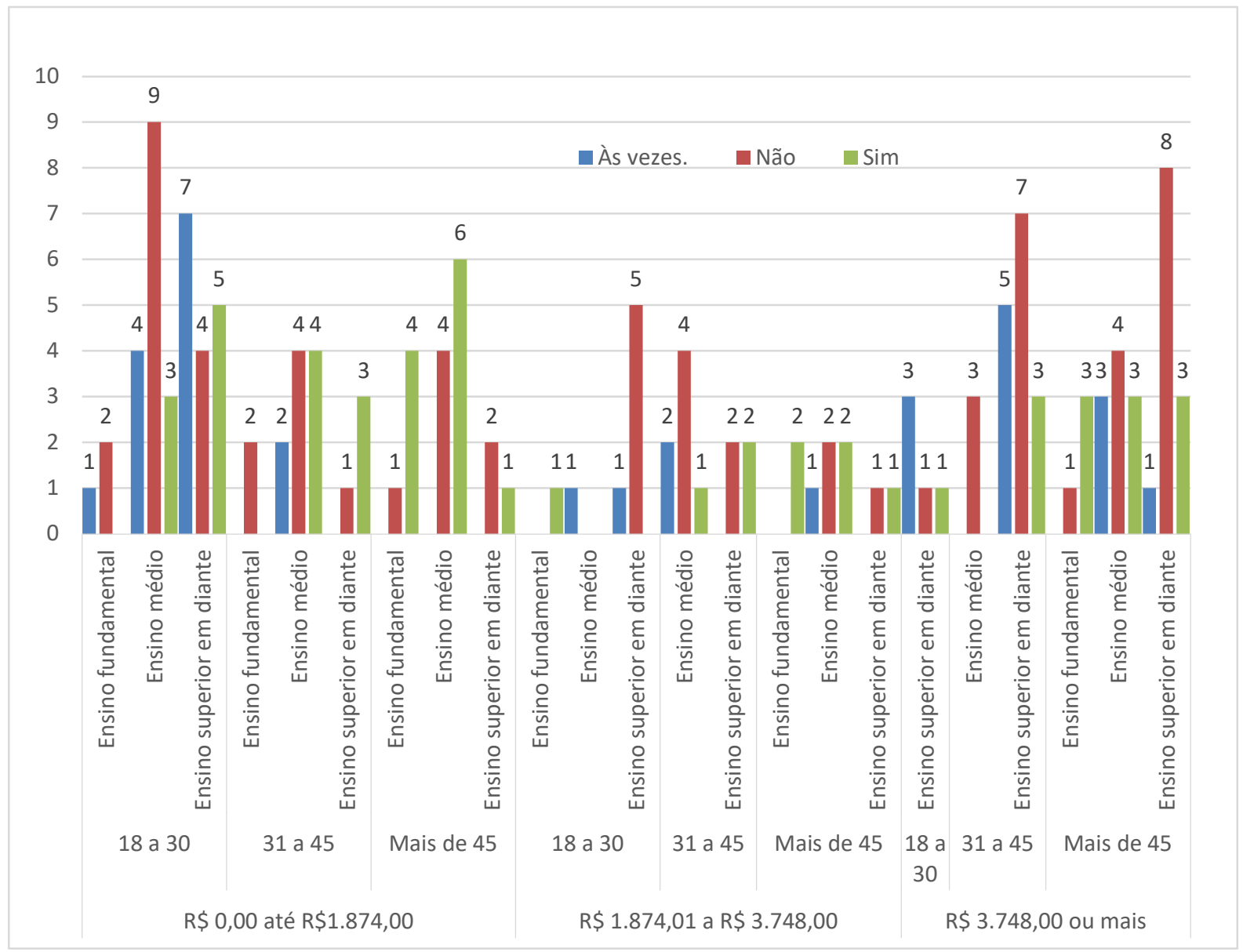

Fonte: Elaborado pelo autor (2019).

Os respondentes que marcaram ter receio quanto à segurança de suas informações nos aplicativos foram 48. Dentro desse grupo, destacou-se o perfil com mais de 45 anos, ensino médio e renda de até $\mathrm{R} \$ 1.874,00$, seguido do perfil de 18 a 30 anos, ensino superior em diante e renda também de R $\$ 1.874,00$, com diferença de apenas um respondente a menos como exibe o gráfico 7.

Dos respondentes que marcaram “às vezes”, relativizando a segurança das suas informações nos aplicativos, o perfil que se destacou possuia entre 18 a 30 anos, ensino superior ou mais, e renda de até $\mathrm{R} \$ 1.874,00$, totalizando 31 pessoas. Este número demonstra a quantidade de pessoas que certamente faz uso, mas que, mesmo assim, não se sentem completamente seguras quanto à privacidade dos seus dados. As pessoas que alegaram não ter receio quanto à segurança das informações nos aplicativos foram 67. O perfil em destaque, com 9 respondentes, possuía 18 a 30 anos, ensino médio e renda de até $\mathrm{R} \$ 1.874,00$. Seguido do perfil com mais de 45 anos, ensino superior em diante e renda acima de $\mathrm{R} \$ 3.748,00$ com apenas um respondente a menos. 


\section{Gráfico 8 - Sinto-me vulnerável ao retirar dinheiro nos ATMs.}

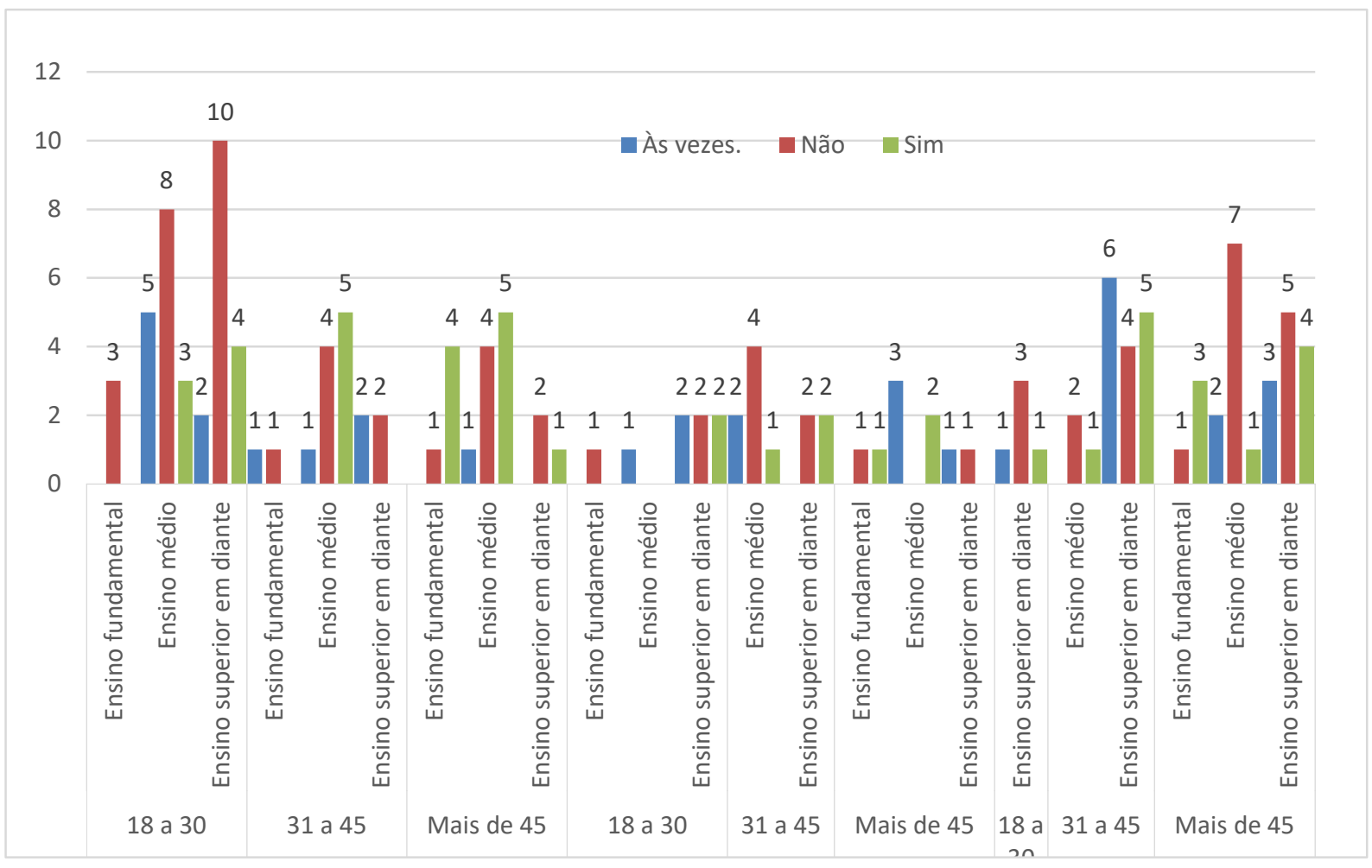

Fonte: Elaborado pelo autor (2019).

De acordo com o gráfico 8, quando questionados se se sentiam vulneráveis ao retirar dinheiro nos autoatendimentos, a maioria afirmou que não. O perfil desse público que mais se repetiu foi com idade entre 18 a 30 anos, ensino superior em diante e renda de até $\mathrm{R} \$ 1.874,00$. No total, 68 respondentes marcaram essa opção. Dos respondentes que afirmaram sentir-se vulnerável ao retirar dinheiro nos autoatendimentos, foram um total de 45. Três perfis tiveram a mesma quantidade de respondentes, os do ensino médio, com renda de até $\mathrm{R} \$ 1.874,00$ divididos entre 31 a 45 anos e mais de 45 anos, e o perfil com ensino superior em diante e renda acima de $\mathrm{R} \$ 3.748,00$.

O total de respondentes que marcou sentir-se vulnerável ao retirar dinheiro nos autoatendimentos foi de 33 pessoas. O perfil em destaque possuía renda acima de $\mathrm{R} \$ 3.748,00$, ensino superior e idade entre 31 a 45 anos, seguido do perfil com renda até $\mathrm{R} \$ 1.874,00$, ensino médio e idade de 18 a 30 anos, com apenas um respondente a menos. 
Gráfico 9 - Prefiro o atendimento presencial.

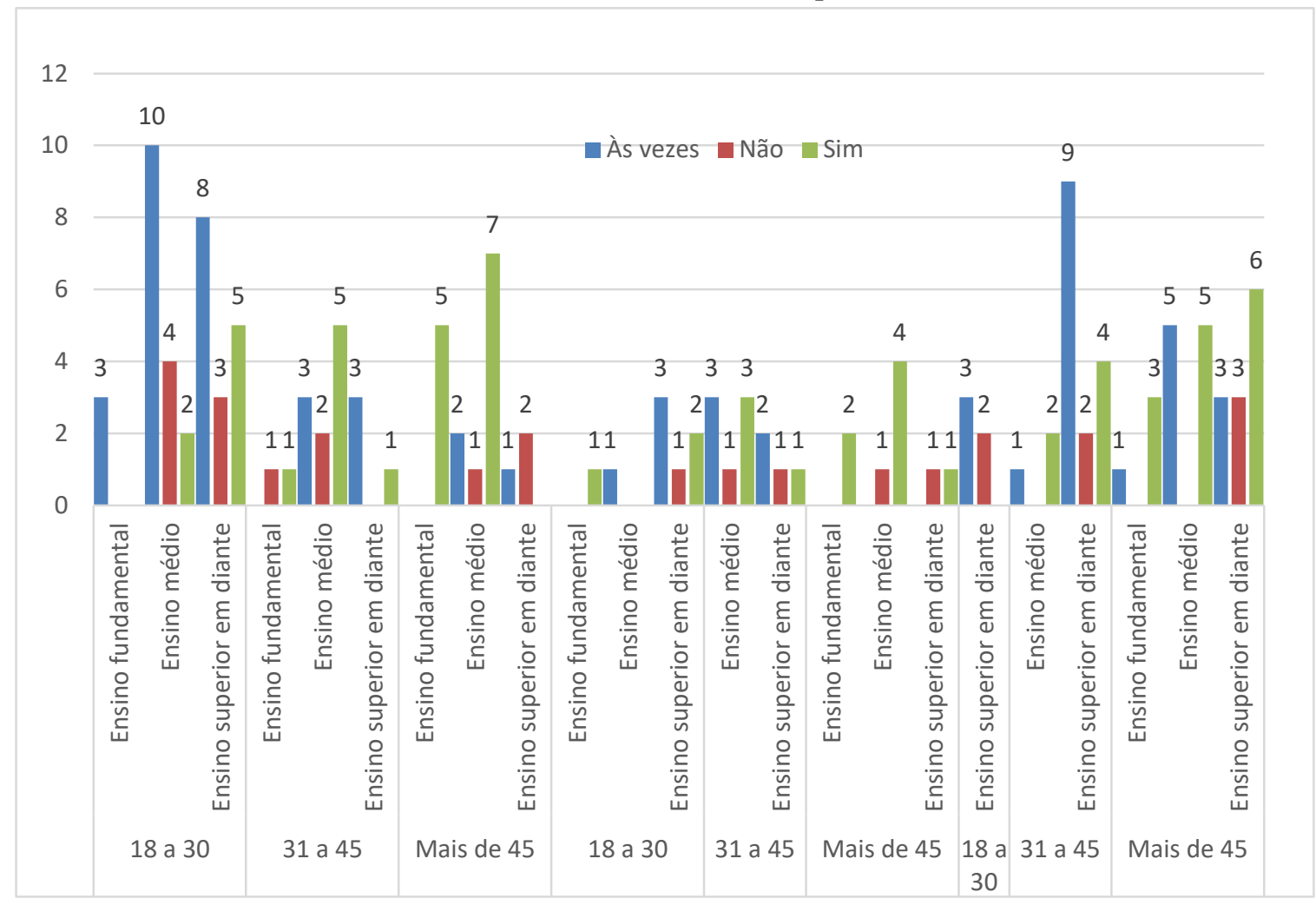

Fonte: Elaborado pelo autor (2019).

Quando questionados se preferem o atendimento presencial, por apenas um respondente a mais, a resposta “Às vezes" foi a mais marcada pelos entrevistados com um total de 61 pessoas. O perfil com maior número de respondentes possuía de 18 a 30 anos, ensino médio e renda de até $\mathrm{R} \$ 1.874,00$. O segundo perfil que teve destaque afirmaram preferir o atendimento presencial, com 60 respondentes, representados pela maioria de mais de 45 anos, ensino médio e renda de até $\mathrm{R} \$ 1.874,00$. O público que se destacou por negar preferir o atendimento presencial possuía de 18 a 30 anos, ensino médio e renda de até R\$1.874,00. No total, 25 pessoas marcaram essa opção conforme aponta o gráfico 9.

\subsection{Teste Exato de Fisher}

O teste exato de Fisher serve para testar a hipótese de que duas variáveis, apresentadas em uma tabela 2x2, estão associadas. Para atender as suposições do teste, precisamos de amostras aleatórias e independentes; duas classes mutuamente exclusivas; nível de mensuração em escala no mínimo nominal. Em tabelas cruzadas 2 x 2, os valores esperados menores que 5 e amostras pequenas, podem afetar a aproximação da distribuição Qui-Quadrado. Por isso, o teste exato de Fisher é o mais adequado.

Para as análises subdividimos as variáveis idades e nível de escolaridade por categoria, de maneira que teremos seis variáveis dummy, com 1 sendo ter a característica e 0 não ter a característica de interesse.

\subsection{Resultados}

As Tabelas I, II e III apresentam as tabelas de contingência entre as categorias da variável 'idade’ e a variável 'dificuldade de uso dos canais eletrônicos'. 
Tabela I -Contingência entre a categoria 'Idade entre 18 e 30 anos' e 'dificuldade de uso dos canais eletrônicos'.

\begin{tabular}{|c|c|c|}
\hline \multirow{2}{*}{$\begin{array}{c}\text { Idade entre 18 e } \\
30 \text { anos }\end{array}$} & \multicolumn{2}{|c|}{$\begin{array}{c}\text { Dificuldade de uso } \\
\text { dos canais eletrônicos }\end{array}$} \\
\cline { 2 - 3 } & Não & Sim \\
\hline Não & 57 & 41 \\
\hline Sim & 39 & 9 \\
\hline
\end{tabular}

Tabela II - Contingência entre a categoria ‘Idade entre 31 e 45 anos' e 'dificuldade de uso dos canais eletrônicos'.

\begin{tabular}{|c|c|c|}
\hline \multirow{2}{*}{$\begin{array}{c}\text { Idade entre 31 e } \\
45 \text { anos }\end{array}$} & \multicolumn{2}{|c|}{$\begin{array}{c}\text { Dificuldade de uso } \\
\text { dos canais } \\
\text { eletrônicos }\end{array}$} \\
\cline { 2 - 3 } & Não & Sim \\
\hline Não & 61 & 40 \\
\hline Sim & 35 & 10 \\
\hline
\end{tabular}

Tabela III - Contingência entre a categoria 'Idade acima dos 45 anos' e 'dificuldade de uso dos canais eletrônicos'.

\begin{tabular}{|c|c|c|}
\hline \multirow{2}{*}{$\begin{array}{c}\text { Idade acima de } \\
45 \text { anos }\end{array}$} & \multicolumn{2}{|c|}{$\begin{array}{c}\text { Dificuldade de uso } \\
\text { dos canais } \\
\text { eletrônicos }\end{array}$} \\
\cline { 2 - 3 } & Não & Sim \\
\hline Não & 74 & 19 \\
\hline Sim & 22 & 31 \\
\hline
\end{tabular}

Tabela IV - Resultados dos testes exato de Fisher para o cruzamento entre as categorias das variáveis 'idade' e 'dificuldade de uso dos canais eletrônicos'

\begin{tabular}{|c|c|}
\hline Cruzamento & P-valor do teste \\
\hline Entre 18 e 30 anos e Dificuldade & 0,0057 \\
\hline Entre 31 e 45 anos e Dificuldade & 0,0582 \\
\hline Acima dos 45 anos e Dificuldade & 0,0000 \\
\hline
\end{tabular}

De acordo com o teste exato de Fisher, a hipótese nula de significância da associação (contingência) entre os dois tipos de classificação foi rejeitada para as categorias entre 18 e 30 anos e acima dos 45 anos de idade, ao nível de significância 5\%. Ou seja, a categoria que tem associação com a dificuldade de uso dos canais eletrônicos é a entre 31 e 45 anos, e, mesmo assim, um valor muito próximo do nível de significância alfa, 0,05.

As Tabelas V, VI, VII apresentam as tabelas de contingência entre as categorias da variável 'escolaridade' e a variável 'dificuldade de uso dos canais eletrônicos'. 
Tabela V - Contingência entre a categoria ensino fundamental e 'dificuldade de uso dos canais eletrônicos'.

\begin{tabular}{|c|c|c|}
\hline \multirow{2}{*}{$\begin{array}{c}\text { Ensino } \\
\text { Fundamental }\end{array}$} & \multicolumn{2}{|c|}{$\begin{array}{c}\text { Dificuldade de uso } \\
\text { dos canais eletrônicos }\end{array}$} \\
\cline { 2 - 3 } & Não & Sim \\
\hline Não & 92 & 37 \\
\hline Sim & 4 & 13 \\
\hline
\end{tabular}

Tabela VI - Contingência entre a categoria ensino médio e 'dificuldade de uso dos canais eletrônicos'.

\begin{tabular}{|c|c|c|}
\hline \multirow{2}{*}{ Ensino Médio } & \multicolumn{2}{|c|}{$\begin{array}{c}\text { Dificuldade de uso dos } \\
\text { canais eletrônicos }\end{array}$} \\
\cline { 2 - 3 } & Não & Sim \\
\hline Não & 56 & 28 \\
\hline Sim & 40 & 22 \\
\hline
\end{tabular}

Tabela VII - Contingência entre a categoria ensino superior e 'dificuldade de uso dos canais eletrônicos'.

\begin{tabular}{|c|c|c|}
\hline \multirow{2}{*}{$\begin{array}{c}\text { Ensino } \\
\text { Superior }\end{array}$} & \multicolumn{2}{|c|}{$\begin{array}{c}\text { Dificuldade de uso dos } \\
\text { canais eletrônicos }\end{array}$} \\
\cline { 2 - 3 } & Não & Sim \\
\hline Não & 44 & 35 \\
\hline Sim & 52 & 15 \\
\hline
\end{tabular}

Tabela VIII - Resultados dos testes exato de Fisher para o cruzamento entre as categorias das variáveis 'escolaridade' e 'dificuldade de uso dos canais eletrônicos'

\begin{tabular}{|c|c|}
\hline Cruzamento & P-valor do teste \\
\hline Ensino fundamental e Dificuldade & 0,0002 \\
\hline Entre médio e Dificuldade & 0,8605 \\
\hline Acima superior e Dificuldade & 0,0083 \\
\hline
\end{tabular}

De acordo com o teste exato de Fisher, a hipótese nula de significância da associação (contingência) entre os dois tipos de classificação foi rejeitada para as categorias ensino fundamental e ensino superior, ao nível de significância 5\%. Ou seja, a categoria que tem associação com a dificuldade de uso dos canais eletrônicos é a ensino médio.

\section{Conclusões}

Nos principais setores da sociedade, há uma forte tendência em readequação de processos, de forma que toda a sua prestação de serviço se dê por meio das TICs. A nova estrutura bancária une sistematização, automação e autoatendimento para alavancar seus negócios, e, nesse contexto, torna-se importante o avanço tecnológico de forma a considerar os principais envolvidos no processo, os usuários dos serviços bancários.

Por meio das análises realizadas sobre as limitações digitais encontradas pelos clientes diante da nova estrutura bancária, verificou-se um reduzido número de pessoas que possuem a limitação digital do acesso. É importante destacar que a amplitude com que as TICs têm chegado a inúmeras searas sociais, conjugada a políticas públicas orientadas para um mercado digital cada vez mais global, leva a crer em um gradual decréscimo dessa limitação ao longo do tempo.

Quanto às limitações cognitivo-informacionais dos usuários que alegaram não utilizar qualquer ferramenta tecnológica, nenhum destes possuía ensino superior e, em sua maioria, tinham mais de 45 anos. O perfil de 
respondentes que revelou possuir mais dificuldade em utilizar os canais eletrônicos teve prevalência entre o público com mais de 45 anos e com escolaridade até o ensino médio.

As limitações comportamentais, de forma geral, também apresentaram maior frequência entre os usuários com mais de 45 anos, ensino médio e renda de até $\mathrm{R} \$ 1.874,00$. Conquanto, o mesmo perfil que demonstrou ser adepto das TICs para realizar suas transações financeiras, afirmou que às vezes prefere o atendimento presencial, demonstrando que fazem uso, mas considera também importante, a depender da situação, $o$ atendimento presencial.

A pesquisa sobre resistência ao uso das TICs nos serviços bancários torna-se imprescindível para a prática efetiva da gestão dos serviços prestados, uma vez que compreender o perfil sociodemográfico dos clientes quanto a suas limitações digitais instiga o setor a desenvolver ações que promovam a mitigação das barreiras encontradas pelos usuários, de forma a aprimorar sua prestação de serviço de acordo com a realidade do cliente. A estrutura do questionário, desenvolvida sistematicamente conforme o modelo de limitações ao uso das TICs, evidenciou que tais limitações são melhor compreendidas quando tratadas de forma interdependentes, reforçando que, apesar de existir uma tendência em alguns grupos sociodemográficos, tratar as limitações no uso das TICs em serviços bancários sob a percepção do usuário torna o processo de aperfeiçoamento complexo e tácito.

O principal desafio da pesquisa foi fazer com que o cliente refletisse e reconhecesse, quando da existência, a possível causa de suas limitações. De forma que, durante o processo de averiguação das principais limitações, fez-se necessário promover o pensamento crítico dos usuários que de fato sequer faziam a utilização, com autonomia, das TICs.

Por ter caráter exploratório, a pesquisa não se estendeu em profundidade nos níveis de limitações. Sugere-se, portanto, que para pesquisas futuras seja estudado o grau da limitação do usuário em fazer o efetivo uso das TICs, bem como que se averigue a correlação entre transações bancárias que indiquem a preferência dos usuários pelo uso dos canais presenciais de atendimento bancário.

\section{Referências}

BELLINI, Carlo Gabriel Porto; GIEBELEN, Edwin; CASALI, Richélita do Rosário Brito. Limitações digitais. Informação \& Sociedade: Estudos, v. 20, n. 2, 2010.

DAVIS, F. D. Perceived Usefulness, Perceived Ease of Use, and User Acceptance of Information Technology, MIS Quarterly (13:3), 1989, pp. 319-339.

DE MELLO, Roberto Agostinho; STAL, Eva; QUEIROZ, Ana Carolina S. O banco na Internet: inovações em tecnologia da informação moldam novos serviços bancários, 2006.

DEWAN, Sangeev; RIGGANS, Frederick J. The Digital Divid: Currente and Future Research Directions. Journal of the Association for Informations Systems. V. 6, n. 12, p 298-337, 2005.

FEBRABAN, Pesquisa FEBRABAN de Tecnologia Bancária. Delloite, 2017.

GIL, A. C. Como elaborar projetos de pesquisa. 4 ed. São Paulo: Atlas, 2002.

HEIDEMANN, Leonardo Albuquerque; ARAUJO, Ives Solano; VEIT, Eliane Angela. Um referencial teóricometodológico para o desenvolvimento de pesquisas sobre atitude: a Teoria do Comportamento Planejado de Icek Ajzen. Revista electrónica de investigación en educación en ciencias-REIEC, ISSN, v. 6666, p. 1$10,1850$.

HSIEH, J.J. Po-An; RAI, Arun; KEIL, Mark. Understanding Digital Inequality: Comparing Continued Use Behavioral Models of the Socio-economically Advantaged and Disadvantaged. MIS Quaterly. V. 32, n. 1, p 97-126, 2008.

KIM, Hee-Woong; KANKANHALLI, Atreyi. Investigating user resistance to information systems implementation: a stats quo bias perspective. MIS Quaterly. V. 33, n.4, p 567-582, 2009.

MOGHADAM, BAYTOLLAH AKBARI. Does ICT Advertising Affect the ICT Banking Effectiveness? A Three Dimensional Model for Iran. Journal of ICT Banking \& Commerce. V. 17, 2012.

SAMARA, B. S.; BARROS, J.C. Pesquisa de marketing: conceitos e metodologia. São Paulo: Makron Books, 2002.

SARANYA, J. A Empirical Study on Role of ICT in Banking Sector. International Journal of Multidisciplinary and Current Research, V. 2, 2014. 
YOUSAFZAI, S. A literature review of theoretical models of ICT banking adoption at the individual level. Journal of Financial Services Marketing, 2012. 